\title{
Functional inactivation of OsGCNT induces enhanced disease resistance to Xanthomonas oryzae pv. oryzae in rice
}

\author{
Xia Xu, Zheng Chen, Yong-feng Shi, Hui-mei Wang, Yan He, Lei Shi, Ting Chen, Jian-li Wu and Xiao-bo Zhang ${ }^{*}$ (D)
}

\begin{abstract}
Background: Spotted-leaf mutants are important to reveal programmed cell death and defense-related pathways in rice. We previously characterized the phenotype performance of a rice spotted-leaf mutant sp/21 and narrowed down the causal gene locus sp/21(t) to an 87-kb region in chromosome 12 by map-based cloning.

Result: We showed that a single base substitution from A to $G$ at position 836 in the coding sequence of Oryza sativa beta-1,6-N-acetylglucosaminyl transferase (OsGCNT), effectively mutating Tyr to Cys at position 279 in the translated protein sequence, was responsible for the spotted-leaf phenotype as it could be rescued by functional complementation. Compared to the wild type IR64, the spotted-leaf mutant sp/21 exhibited loss of chlorophyll, breakdown of chloroplasts, down-regulation of photosynthesis-related genes, and up-regulation of senescence associated genes, which indicated that OsGCNT regulates premature leaf senescence. Moreover, the enhanced resistance to the bacterial leaf blight pathogen Xanthomonas oryzae pv. oryzae, up-regulation of pathogenesisrelated genes and increased level of jasmonate which suggested that OsGCNT is a negative regulator of defense response in rice. OsGCNT was expressed constitutively in the leaves, sheaths, stems, roots, and panicles, and OsGCNT-GFP was localized to the Golgi apparatus. High throughput RNA sequencing analysis provided further evidence for the biological effects of loss of OsGCNT function on cell death, premature leaf senescence and enhanced disease resistance in rice. Thus, we demonstrated that the novel OsGCNT regulated rice innate immunity and immunity-associated leaf senescence probably by changing the jasmonate metabolic pathway.
\end{abstract}

Conclusions: These results reveal that a novel gene Oryza sativa beta-1,6-N-acetylg/ucosaminyl transferase (OsGCNT) is responsible for the spotted-leaf mutant sp/21, and OsGCNT acts as a negative-regulator mediating defense response and immunity-associated premature leaf senescence probably by activating jasmonate signaling pathway.

Keywords: Oryza sativa L., Spotted-leaf, OsGCNT, Premature leaf senescence, Defense response

\section{Background}

Programmed cell death (PCD) refers to the genetically controlled death of a cell [1]. It is well known that PCD plays a fundamental role in varieties of biological functions including innate immunity in plants. Plants have evolved complicated mechanisms to defend themselves from pathogen infections [2]. The hypersensitive response (HR), a type of PCD, is the most common characteristic of plant disease resistance, which triggers rapid cell death to inhibit further invasion of pathogens in host plant tissues

\footnotetext{
* Correspondence: beishangd@163.com; 13989818328@163.com State Key Laboratory of Rice Biology, Chinese National Center for Rice Improvement, China National Rice Research Institute, Hangzhou 310006, China
}

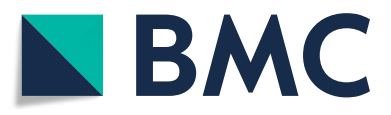

(c) The Author(s). 2018 Open Access This article is distributed under the terms of the Creative Commons Attribution 4.0 International License (http://creativecommons.org/licenses/by/4.0/), which permits unrestricted use, distribution, and reproduction in any medium, provided you give appropriate credit to the original author(s) and the source, provide a link to the Creative Commons license, and indicate if changes were made. The Creative Commons Public Domain Dedication waiver (http://creativecommons.org/publicdomain/zero/1.0/) applies to the data made available in this article, unless otherwise stated.

[3]. Lesion mimic mutants (LMMs) or the specifically termed spotted-leaf ( $\mathrm{spl}$ ) mutants in rice could produce necrotic lesions similar to that caused by HR without pathogen infection, abiotic stress or mechanical damage [4]. In fact, it has been reported that numerous rice spl mutants display significantly enhanced disease resistance to multiple pathogens $[5,6]$. The identification and characterization of novel spl mutants would facilitate the elucidation of mechanisms involved in plant innate immunity.

Leaf senescence, as the last stage of leaf development, is an important biological process [7]. However, premature leaf senescence affects crop yield and biomass production [8]. It has been observed that many spl mutants exhibit 
spontaneous cell death in pre-senescent green leaves under normal growth conditions [7]. In recent years, many spl mutants have been identified and the causal genes have been cloned. In rice, these genes encode various types of proteins such as zinc finger protein [9], extracellular leucine-rich repeat (eLRR) domain protein [10], hypersensitive induced reaction protein [11], clathrin-associated adaptor protein [12], coproporphyrinogen III oxidase [13], nucleotide-binding site containing protein leucine-rich repeat (NBS-LRR) protein [14, $15]$, splicing factors [16, 17], mitogen-activated protein kinase kinase kinase (MAPKKK) [18, 19], E3 ubiquitin ligases [20-22], UDP-N-acetylglucosamine pyrophosphorylase [23], AAA-type ATPase [2, 24], eukaryotic translation elongation factor $[3,25]$, subunit of the light-harvesting complex I [26], and proteins involved in biochemical pathways of eukaryotic release factor 1 responsible for salicylic acid (SA)-dependent defense response [27]. The wide range of protein categories indicates leaf senescence is not only important but also a complicated biological process. Nevertheless, the identification and characterization of more novel spl mutants may be helpful to elucidate the mechanism of immunity-associated leaf senescence in plants.

Glycosyltransferases (GTs; EC 2.4.x.y) belong to a superfamily, and their biochemical reactions are associated with the formation of glycosidic bonds through the transfer of sugars from activated donor molecules to a wide range of lipophilic small molecule acceptors including lipids, proteins, hormones, secondary metabolites, and oligosaccharides [28]. It has been reported that GTs are involved in many biological processes including metabolic regulation, synthesis of diverse secondary metabolites, modification of hormones and cell wall synthesis [29]. In CAZy (Carbohydrate Active Enzyme) database, rice genome contains 609 potential GT members which have been grouped into 40 gene families. The beta-galactoside beta-1-6- and beta-1-3-N-acetylglucosaminyltransferases (beta-1-6GnT and beta-1-3GnT) that synthesize blood group I and i antigens were first identified in rat tissues [30]. In human, beta-1,6-N-acetylglucosaminyltransferase is classified into two types, the core 2-branching enzyme and I-branching enzyme. It has been found that Core 2 beta-1,6-N-acetylglucosaminyltransferase1 (GCNT1) expression in prostate biopsy specimen is an indicator of prostate cancer aggressiveness [31], and I-branching glucosaminyl (N-acetyl) transferase 2 (GCNT2) expression is also significantly correlated to the metastatic phenotype in breast tumor samples [32]. However, the function of GCNT in plants is still largely unknown.

In our previous study, we isolated the rice spotted-leaf mutant spl21 and mapped the causal gene locus $\operatorname{spl21}(t)$ to an $87-\mathrm{kb}$ region in chromosome 12 [33]. Here, we show that spl21(t) (LOC_Os12g42420) encodes a novel
Oryza sativa beta-1,6-N-acetylglucosaminyl transferase (OsGCNT). Functional complementation, high-throughput mRNA sequencing (RNA-seq), plant hormone level determination, and gene functional analysis suggest that a single base substitution in OsGCNT is responsible for the spotted-leaf phenotype including defense response and premature leaf senescence in rice. These results indicate that loss of OsGCNT function is associated with programmed cell death and enhances disease response probably by activating the jasmonate signaling pathway.

\section{Results \\ Map-based cloning of OsGCNT}

The $s p l 21(t)$ locus was previously delimited to an $87 \mathrm{~kb}$ region in rice chromosome 12 [33]. To fine-map the locus, an additional $453 \quad \mathrm{~F}_{2}$ individuals with the spotted-leaf phenotype were genotyped and the $s p l 21(t)$ locus was further refined to an $83 \mathrm{~kb}$ region spanning 13 ORFs (Fig. 1a). Sequence comparison of those ORFs cloned from both the mutant spl21 and WT, we detected only one nonsynonymous mutation (A836G, Y279C) in the ORF LOC_Os12g42420. The other 12 ORFs did not have any mutation compared to their respective wild-type loci (Fig. 1b). The 2465 bp LOC_Os12g42420 contains 2 exons, 1 intron, and thus was considered the most likely candidate gene responsible for the spotted-leaf phenotype.

To verify whether the single base substitution in $L O C_{-}$Os12g42420 was responsible for the spl21 phenotype, the complementary vector $\mathrm{pC} 1300-\mathrm{C}$ harboring the wild type allele was introduced into the mutant embryogenic calli by Agrobacterium tumefaciens-mediated transformation. A total of 28 positive independent $\mathrm{T}_{0}$ transformants were obtained and all exhibited the normal green leaf color without lesions throughout their entire growth period. The results demonstrated that the WT allele could rescue the spotted-leaf phenotype and was indeed the target gene (Fig. 2a-c). Furthermore, spl21 shows the low level of chlorophyll contents at different leaf developmental stages and a high level of $\mathrm{H}_{2} \mathrm{O}_{2}$ accumulation at/around leaf lesions with a high malonaldehyde (MDA) content compared to WT [33]. We measured the contents of chlorophyll a (Chl a), chlorophyll b (Chl b), total of chlorophyll (Chl T), carotenoids (Car) and MDA in the complemented plants to determine whether they were restored to the wild-type levels. The MDA contents in both the complementation lines and WT plants were similar and significantly lower than that of spl21. While the contents of $\mathrm{Chl} \mathrm{a,} \mathrm{Chl} \mathrm{b}$ and Car in complementation lines and WT were similar but significantly higher than that of spl21, indicating that they recovered to the level of WT (Fig. 2d). Taken together, our results demonstrated that 


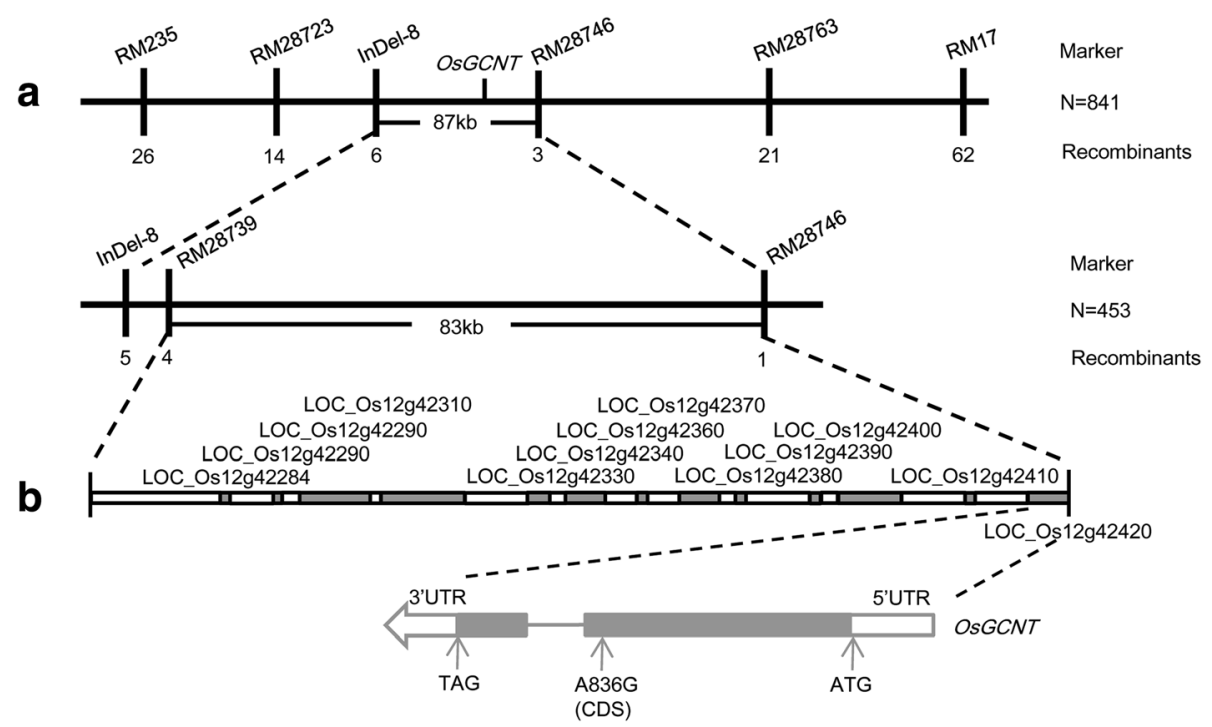

Fig. 1 Map-based cloning of OsGCNT. a OsGCNT locus is further refined to a 83-kb region between marker RM28746 and RM28739. b Single base substitution at position 836 (A836G, Y279C)

$L O C \_O s 12 g 42420$ was the target gene responsible for the spotted-leaf phenotype of spl21.

According to the sequence comparison between genomic DNA and cDNA, LOC_Os12g42420 is composed of 2 exons separated by 1 intron (Fig. 1b). According to the rice genome annotation database (http://rice.plantbiology.msu.edu), the coding sequence (CDS) of LOC_Os12g42420 consists of 1098 nucleotides, and putatively encodes a protein of 365 amino acid residues with a molecular mass of approximately $41 \mathrm{kD}$. LOC_Os $12 g 42420$ is predicted to encode a putative DNA binding protein which contains a Branch domain spanning the amino acid residues from 82 to 332. The Branch domain-containing proteins consist of two types of beta-1,6-N-acetylglucosaminyl transferase enzymes (I-branching enzyme and core-2 branching enzyme), thus LOC_Os12g42420 is supposed to encode a novel beta-1,6-N-acetylglucosaminyl transferase and we designate the locus as Oryza sativa beta-1,6-N-acetylglucosaminyl transferase (OsGCNT).

There is only one copy of OsGCNT in the rice genome. The OsGCNT homologous genes were identified in 9 species by a BLAST search (Fig. 3a). We then assessed the evolutionary relationships between OsGCNT and its homologues in different species by constructing a bootstrap consensus phylogenetic tree using the neighbour-joining method (Fig. 3b). Sequence comparison indicates that OsGCNT is most comparable to gramineae homologs such as ObGCNT (89\%), BdGCNT (80\%), SbGCNT (80\%), HvGCNT (80\%) and ZmGCNT (79\%) while OsGCNT has a high level of similarity to the dicot AtGCNT (69\%) and a lower similarity to the human HsGCNT1 (20.2\%) (Fig. 3). Notably, the amino acid mutation (Y279C) in rice is located in the Branch domain, and the corresponding site is conserved among different species. The results indicate that $O s G C N T$ is structurally conserved and that the $\mathrm{Y} 279 \mathrm{C}$ mutation is likely critical to its biological function.

\section{OsGCNT is expressed constitutively and OsGCNT-GFP probably localizes to the Golgi apparatus}

To determine the expression pattern of OsGCNT, we performed qRT-PCR analysis on the total RNA of roots, stems, nodes, internodes, leaves, leaf sheaths, panicles, and filling grains from WT. OsGCNT was expressed in all the organs examined. The highest expression was detected in leaves and leaf sheaths at 10 weeks old stage, with relatively weaker expression in roots and stems. Similar tendency of expression levels were observed at the grain filling stage (Fig. 4). These results indicated that OsGCNT was constitutively expressed at all developmental stages of rice.

Most GTs act along a secretory pathway requiring the endoplasmic reticulum and the Golgi body where GTs transfer monosaccharide units to various receptor molecules [34]. To determine the cellular distribution of OsGCNT, TargetP version 1.1 (http://www.cbs.dtu.dk/ services/TargetP/) is first used to predict the subcellular localization, and we found that OsGCNT is predicted to be localized in the secretory pathway with the strongest confidence (reliability class (RC) 1). To determine the actual subcellular localization of OsGCNT, we then carried out a PEG-mediated transient expression of rice protoplasts transformed with OsGCNT-GFP. When pOsGCNT-GFP and pAN580 were introduced into the rice protoplasts, the distribution of OsGCNT-GFP was more pronounced in other locations compared to cytosol-localized GFP (Fig. 5). 


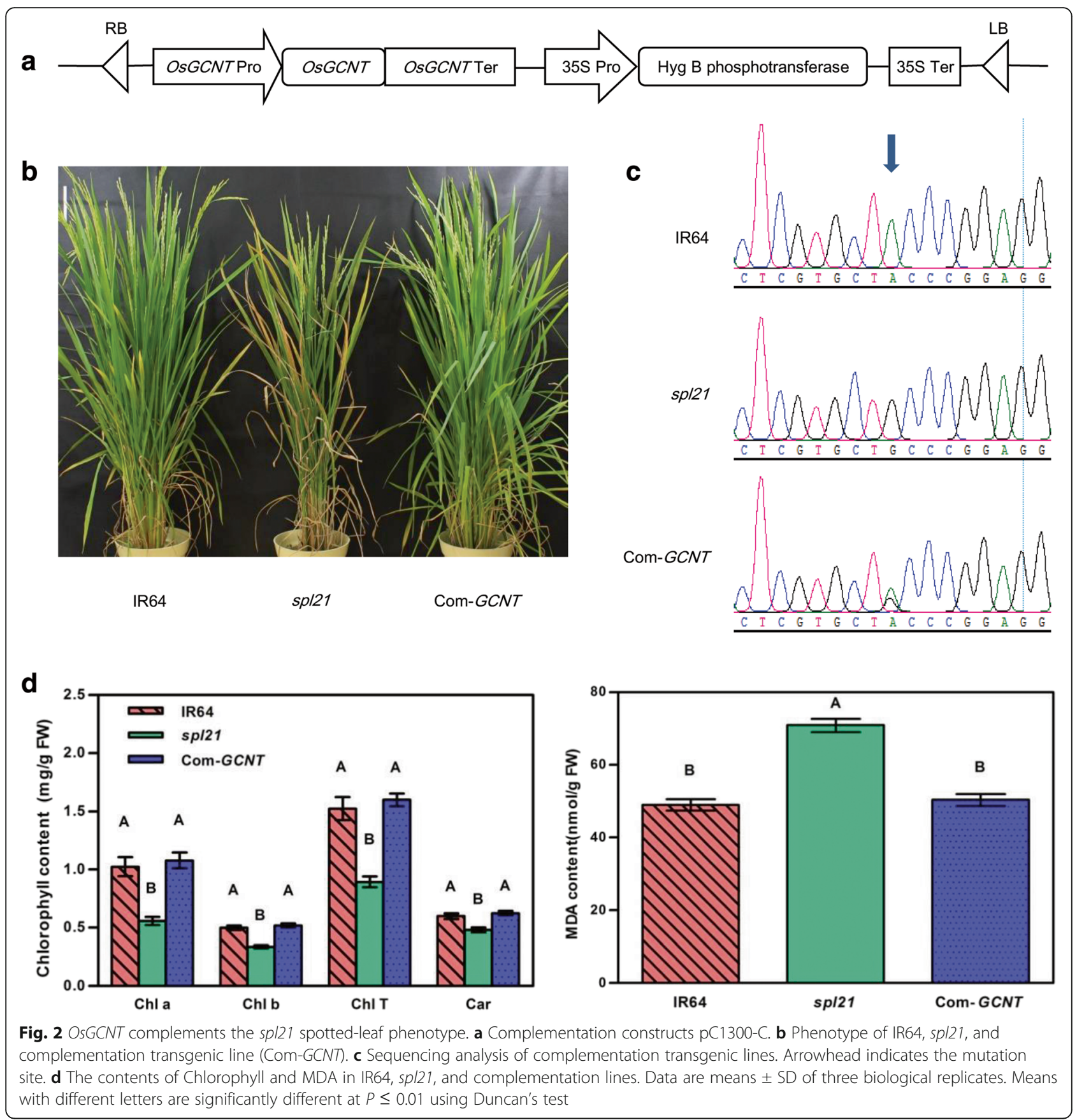

We confirmed the subcellular location of OsGCNT-GFP by expressing it with the Golgi marker, finding that the fusion protein was mainly localized to the Golgi apparatus (Fig. 5). Thus, we concluded that OsGCNT probably localized to the Golgi apparatus.

\section{OsGCNT indirectly regulates premature leaf senescence}

It has been reported that some spl mutants develop spontaneous necrotic lesions accompanied by premature leaf senescence [23]. Decreased level chlorophyll content is used as a critical indicator for the presence of premature leaf senescence [15]. In our previous study, Chl a, Chl b and Car contents in spl21 leaves were all significantly reduced compared to those of WT at different leaf developmental stages [33]. To further investigate the cause of the lower chlorophyll level in the spl21 mutant during senescence, we compared the ultrastructure of chloroplasts in spl21 and WT using transmission electron microscopy (TEM). The normal green leaves of spl21 showed similar chloroplast morphology from mesophyll cells as the WT (Fig. 6a-d), that is, chloroplasts were well-developed with rich lamellae and a small number of 


\section{a} ObGCNT pro BdGCNT .pro SbGCNT pro 2MGCNT.pro HVGCNT pro A.tGCNT . pro MEGCNT . pro DrGCNT . pro HsGCNT1. pro HsGCNT2 pro

OsGCNT . pro ObGCNT . pro BdGCNT pro SbGCNT pro SbGCNT . pro HUGCNT pro AtGCNT pro MEGCNT. pro DrGCNT.pro HsGCNT1.pro HsGCNT2 pro

OsGCNT. pro ObGCNT .pro BaGCNT . pro SbGCNT . pro 2mGCNT pro HVGCNT . pro AtGCNT . pro MEGCNT . pro DEGCNT.pro HsGCNT1.pro HsGCNT2 pro

OsGCNT.pro ObGCNT pro BdGCNT pro BdGCNT . pro SbGCNT . pro 2mGCNT .pro HVGCNT . pro AtGCNT . pro WtGCNT . pro DrGCNT . pro HsGCNT 1.pro HsGCNT2 pro

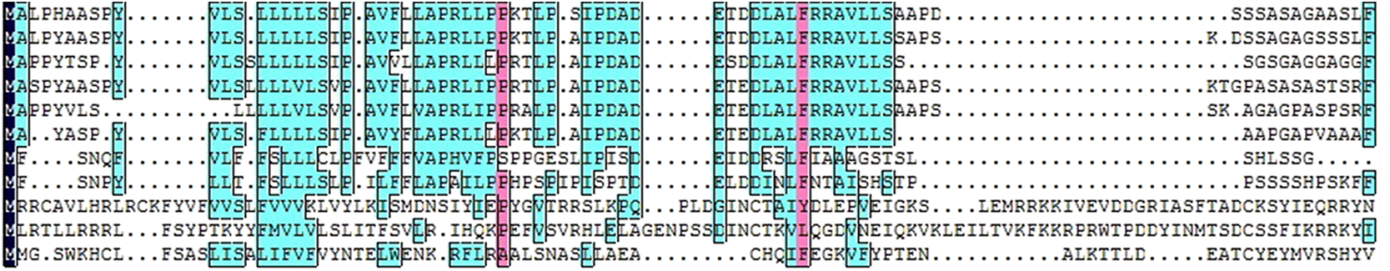

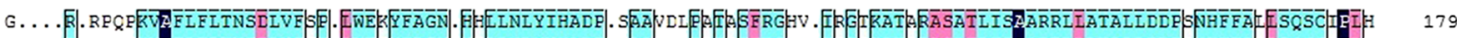

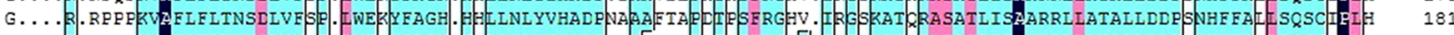

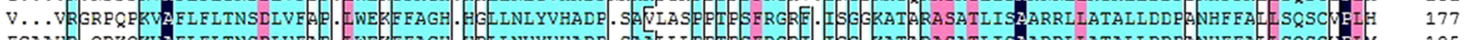

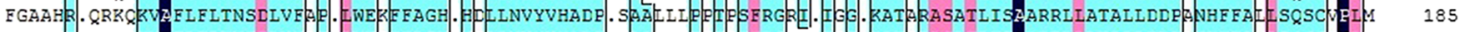

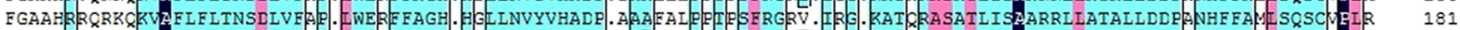

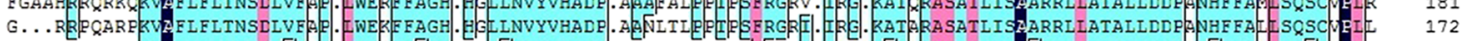

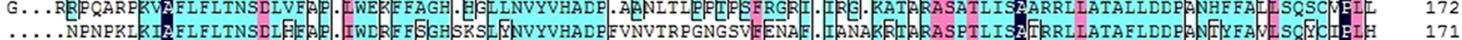

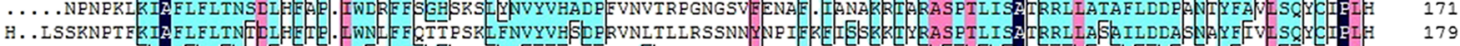

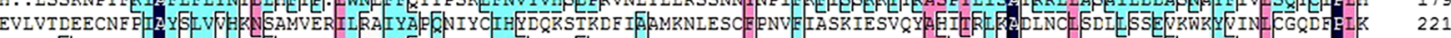

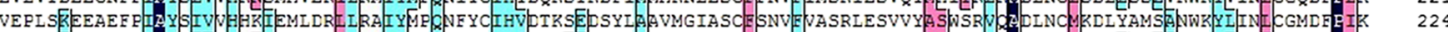

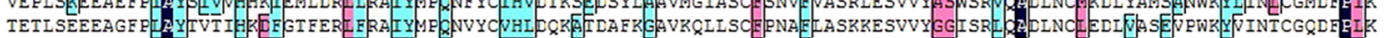

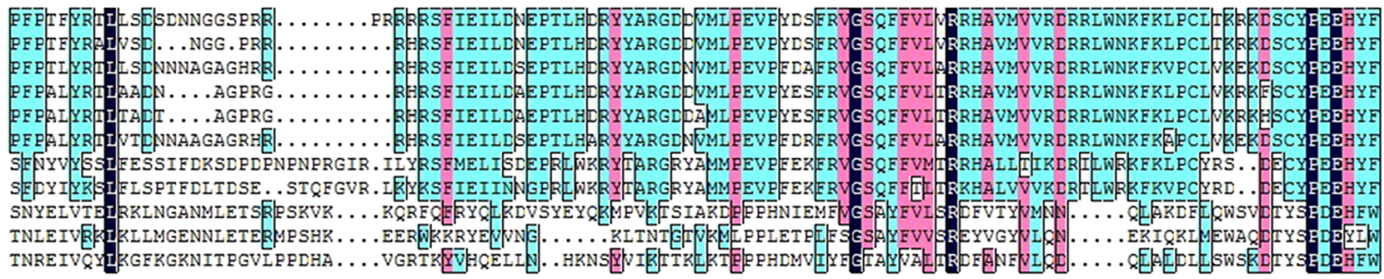

285 281 281 285 281 276

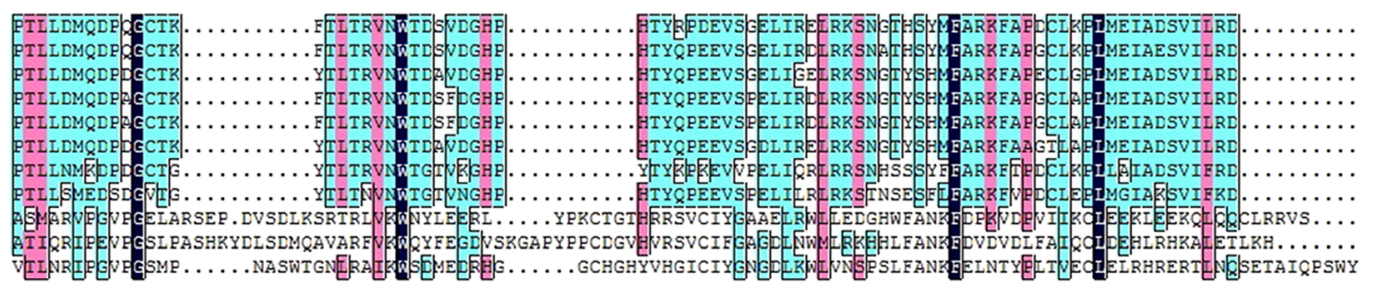

\section{b}

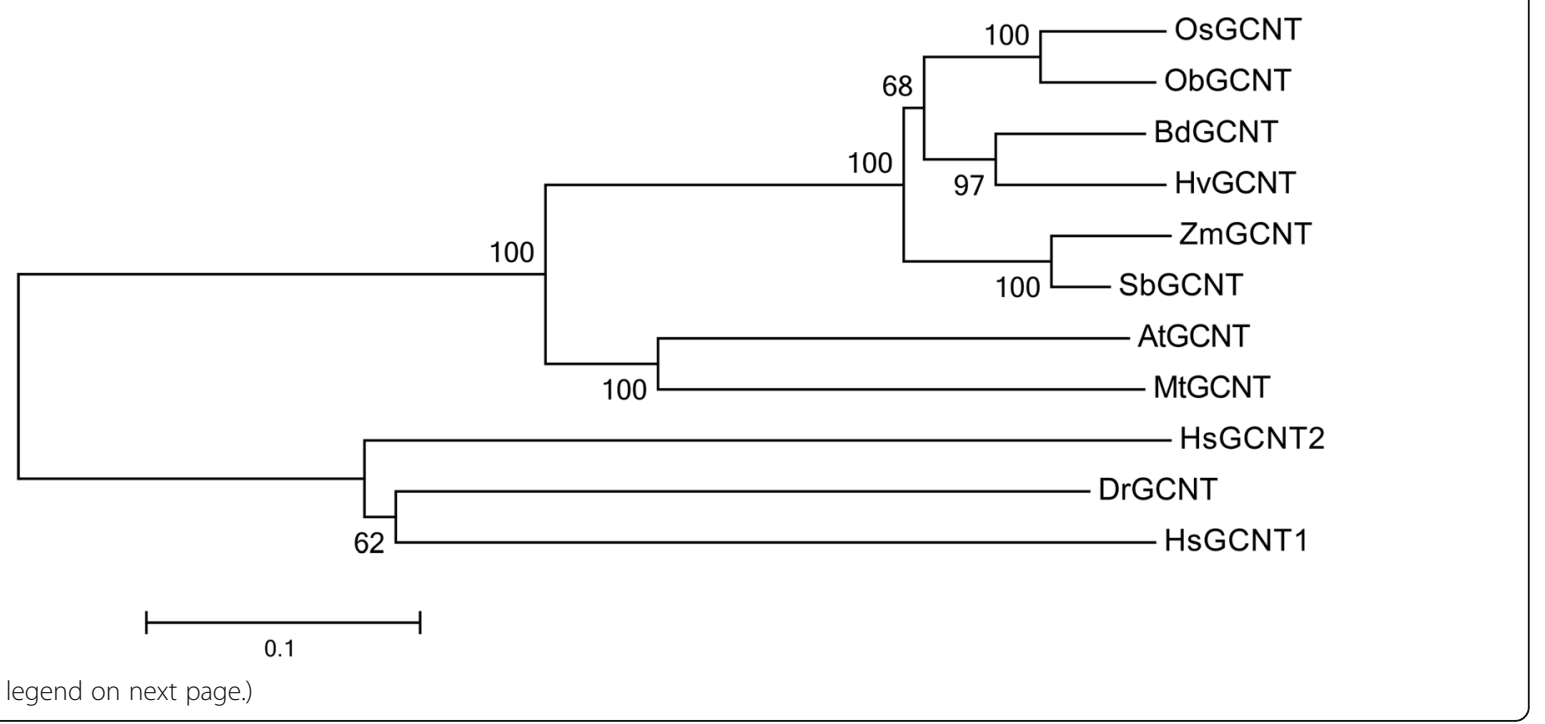


(See figure on previous page.)

Fig. 3 Sequence alignment and phylogenetic analysis of OsGCNT with its homologues. a OsGCNT shares high identity with its homologues, shown by the amino acids highlighted in black. $\mathbf{b}$ Phylogenetic analysis of proteins from different organisms. Phylogenetic tree was constructed by Neighbor-joining method using the MEGA program. Bootstrap values from 100 replicates are indicated at each node. Bar represents the number of amino acid differences per site. All GCNT proteins used and their GenBank accessions are as follows: Oryza sativa OsGCNT (MH181877), Oryza brachyantha ObGCNT (XP_006664213.1), Arabidopsis thaliana AtGCNT (NP_680193.2), Brachypodium distachyon BdGCNT (XP_003577263.1), Zea mays ZmGCNT (XP_008674099.1), Sorghum bicolor SbGCNT (XP_002443582.1), Medicago truncatula MtGCNT (XP_003596911.1), Hordeum vulgare HvGCNT (BAJ85768.1), Danio rerio DrGCNT (NP_963877.1), Homo sapiens HsGCNT1 (NP_001481.2) and Homo sapiens HsGCNT2 (NP_663624.1). Distance scale $=0.1$

osmiophilic bodies. However, disordered structure of thylakoid grana and stroma lamella and degenerated thylakoid membrane were observed in the premature senescent leaves of $s p l 21$ (Fig. 6e, f). These results suggested that the mutation of OsGCNT significantly affected the breakdown of chloroplasts in spl21.

It is well known that leaf senescence is highly associated with various environmental stresses such as darkness [35]. Consequently, darkness treatment is performed frequently to induce synchronous senescence in plants [36]. To reveal whether leaf senescence progress of $s p l 21$ could be accelerated in darkness, we performed darkness treatment on the detached flag leaves from spl21 and WT. After incubation in darkness and light control conditions for five days, the $s p l 21$ leaves exhibited yellowing phenotype while the wide type IR64 leaves remained greener under darkness conditions (Fig. 7a). Thus, we concluded that spl21 leaf senescence progress could be accelerated in darkness.
Leaf senescence is a complex biological process controlled by induced expression of a large number of relevant genes [37]. Among them, a senescence-induced gene, STAY GREEN (SGR), has been reported to regulate chlorophyll degradation [38]. Expression levels of $S G R$ revealed that $S G R$ transcripts were dramatically upregulated in the spl21 mutant at the heading stage (Fig. 7b). It has been shown that the expression levels of many senescence-associated genes (SAGs) and transcription factors (TFs) in spl mutants are upregulated during premature leaf senescence [3]. To further prove that leaf senescence occurred in spl21, we determined the expression of 6 SAGs (Osl2, Osl30, Osl43, Osl85, Osh36 and Osh69), one chlorophyll degradation-related gene (RCCR1), and 2 senescence-associated TFs (OsWRKY23, OsWRKY72) in spl21 and WT at the heading stage, respectively. The results demonstrated that the expression levels of all nine genes were notably increased in the

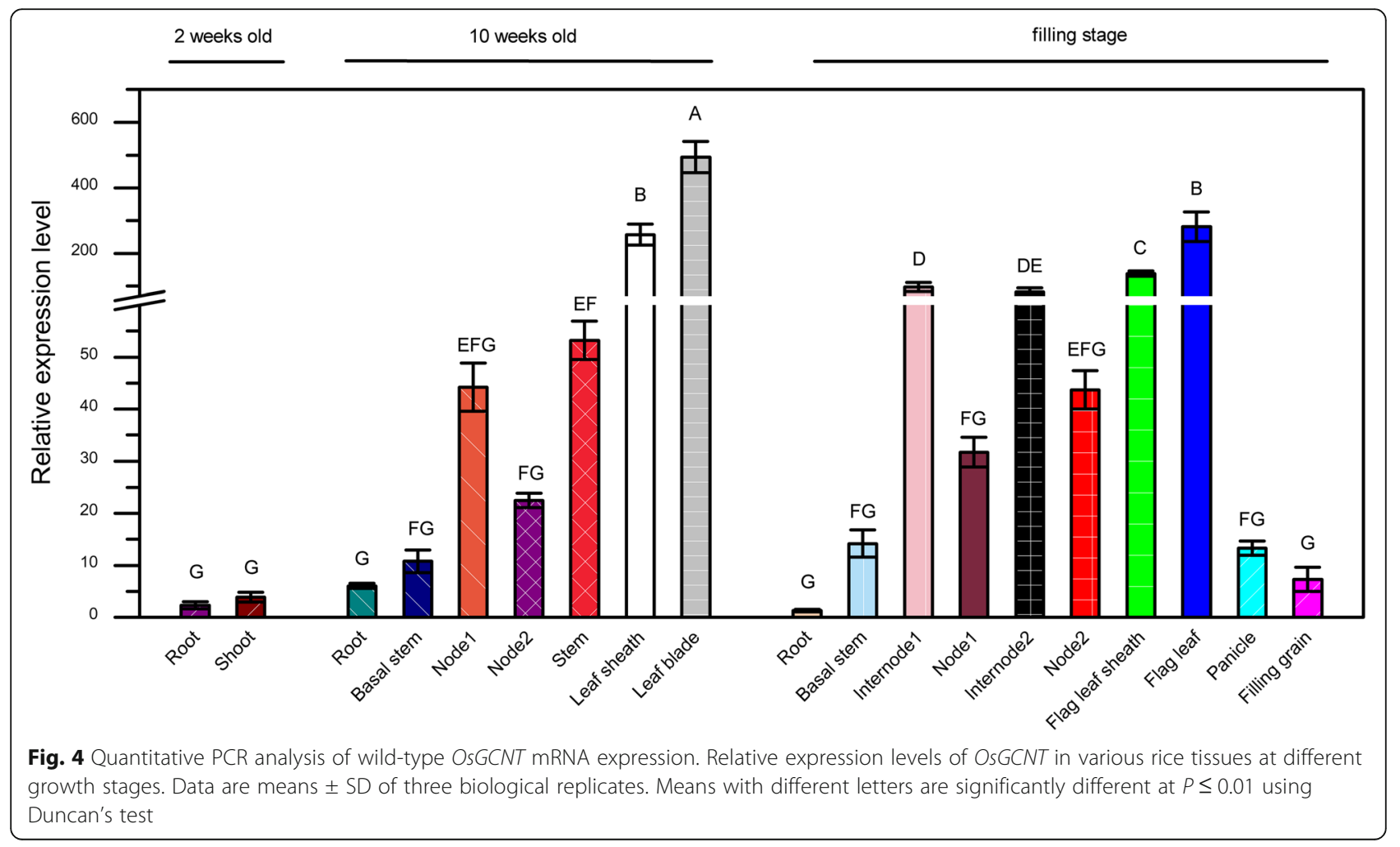




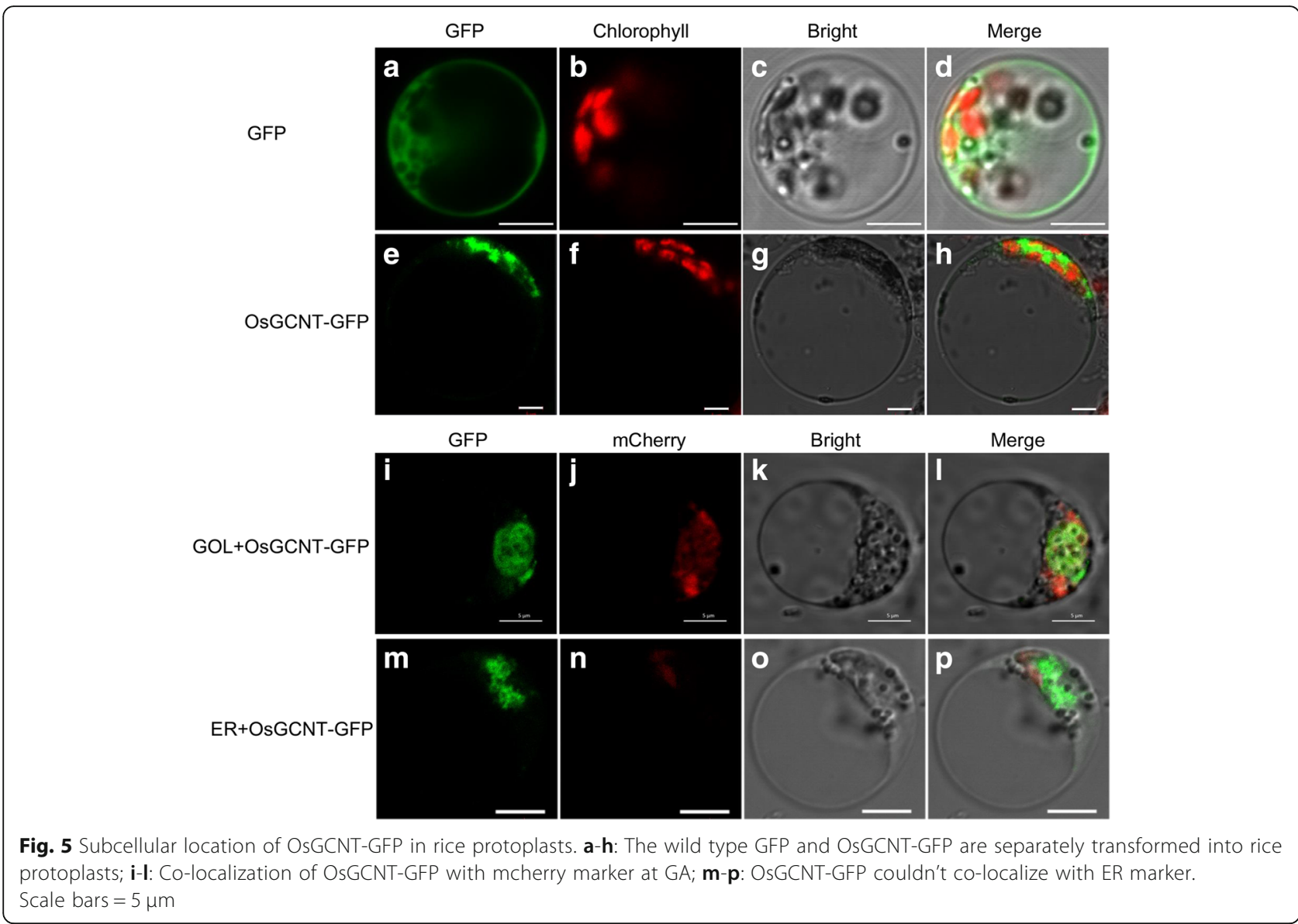

mutant at heading stage in comparison with WT (Fig. 7b), in agreement with the symptom of leaf senescence, indicating that premature leaf senescence of $s p l 21$ was associated with the up-regulation of SAGs.

Leaf senescence is also accompanied by the lower expression of genes related to photosynthesis [7]. We assayed the expression levels of photosynthesis-associated genes including $r b c S$, $l h c A$, $l h c B, r b c L$, psaA, $p s b A$, petD, $n d h A$ and atpA (Fig. 7c). qRT-PCR analysis showed that the mRNA levels of 3 nuclear-encoded genes $(r b c S, l h c A$, $l h c B)$ and 6 chloroplast-encoded genes (rbcL, psaA, psbA, petD, $n d h A$, and $a t p A$ ) were significantly down-regulated in spl21 leaves. These molecular evidences indicated that the OsGCNT mutation was responsible for the premature leaf senescence of $s p l 21$.

\section{OsGCNT regulates defense response}

The typical phenotype of numerous spl mutants is similar to that of HR in plants following infection by invading pathogens [2]. To estimate disease resistance to Xanthomonus oryzae pv. oryzae (Xoo), we inoculated spl21, WT and complemented plants with the virulent Xoo strain PXO99 at the tillering stage. The WT plants and two complemented plants showed longer lesions to
PXO99 while the spl21 plants exhibited a significantly enhanced resistance with shorter lesions on the leaf blades (Fig. 8a, b).Since the differential response patterns of spl21, WT and complemented plants to bacterial blight infection might indicate that the plant systemic resistance to diseases was obviously changed in these lines, we measured the expression levels of 7 defense-response marker genes (PR1a, PR10, PBZ1, PO-C1, EDS1, PAD4 and OsWRKY45) at the tillering stage using relative quantification by qRT-PCR. Our results showed that the mRNAs levels of PR1a, PR10, PBZ1, PO-C1, EDS1, PAD4 and OsWRKY45 in spl21 were highly increased by 121.9-, 7.6-, 13.9-, 57.9-, 38.3-, 16.2-, 5.2-fold, respectively, compared to that of WT (Fig. 8c), indicating that the enhanced level of disease resistance was accompanied by the up-regulation of defense response genes.

\section{Transcriptome sequencing suggests that OsGCNT regulates defense response}

To further explore the global effects of the OsGCNT mutation which could enhance disease resistance and immunity-associated premature leaf senescence of the spl21 mutant, we analyzed gene expression profiles of 

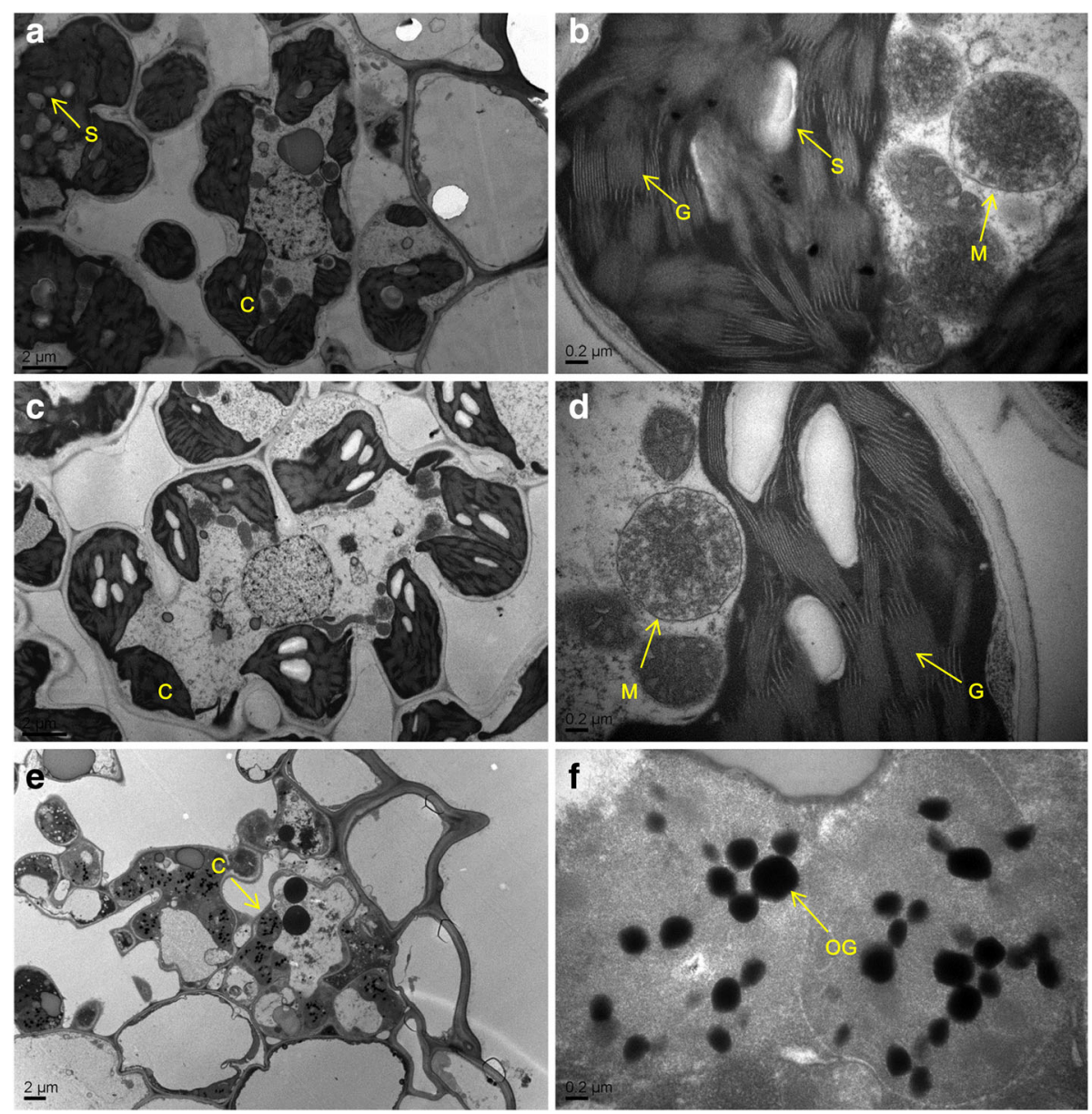

Fig. 6 Ultrastructure of the chloroplast. $\mathbf{a}$ and $\mathbf{b}$ WT; $\mathbf{c}$ and $\mathbf{d}$ the green leaf of $\operatorname{spl} 21 ;(\mathbf{e}, \mathbf{f})$ the premature senescence leaf of $s p / 21$; C, chloroplast; M, mitochondrion; OG, osmiophilic granule; S, starch granule; G, grana thylakoid

spl21 and WT by high-throughput RNA sequencing (RNA-seq). Based on the RNA-seq data, 4315 DEGs were revealed in the spl21 mutant, including 2454 up-regulated and 1861 down-regulated ones.

GO analysis was conducted to classify the DEGs identified in spl21 at the functional level. All the reliable DEGs were analyzed for GO functional enrichment. From the total GO functional enrichment results, functional categories including oxidation-reduction process (GO: 0055114), catalytic activity (GO: 0003824) and kinase activity (GO: 0016301) were significantly enriched in spl21 (Additional file 1: Dataset 1, total group). Notably, enzymatic activity genes involved in response to oxidation-reduction process (GO: 0055114), oxidoreductase activity (GO: 0016491), monooxygenase activity (GO: 0004497), and tetrapyrrole binding (GO: 0046906) were significantly enriched among the 2454 up-regulated genes in spl21 (Additional file 1: Dataset 1, up-regulated group). On the other hand, 1861 down-regulated genes were significantly enriched on photosynthesis (GO: 0015979) and single-organism biosynthetic process (GO: 0044710) (Additional file 1: Dataset 1, down-regulated group). These results demonstrated that OsGCNT might be also involved in photosynthesis and oxidation-reduction processes in rice.

For further investigations of the biological pathways associated with OsGCNT, we mapped the DEGs in the KEGG database and performed enriched pathways between spl21 and WT. The results indicated that the 'biosynthesis of secondary metabolites' (ID: osa01100) was verified as one of the most significantly enriched pathways (Additional file 2: Dataset 2). There were seven pathways significantly enriched for up-regulated genes, and the highly enriched pathways were biosynthesis of secondary metabolites, metabolic pathways and phenylalanine metabolism (Additional file 2: Dataset 2, up-regulated group). The 'metabolic pathways' (ID: osa01100), 'endocytosis' (ID: osa04144) and 'photosynthesis' (ID: osa00061) were highly enriched pathways in down-regulated genes (Additional file 2: Dataset 2, down-regulated group). These results indicated that OsGCNT was likely involved in biosynthesis 


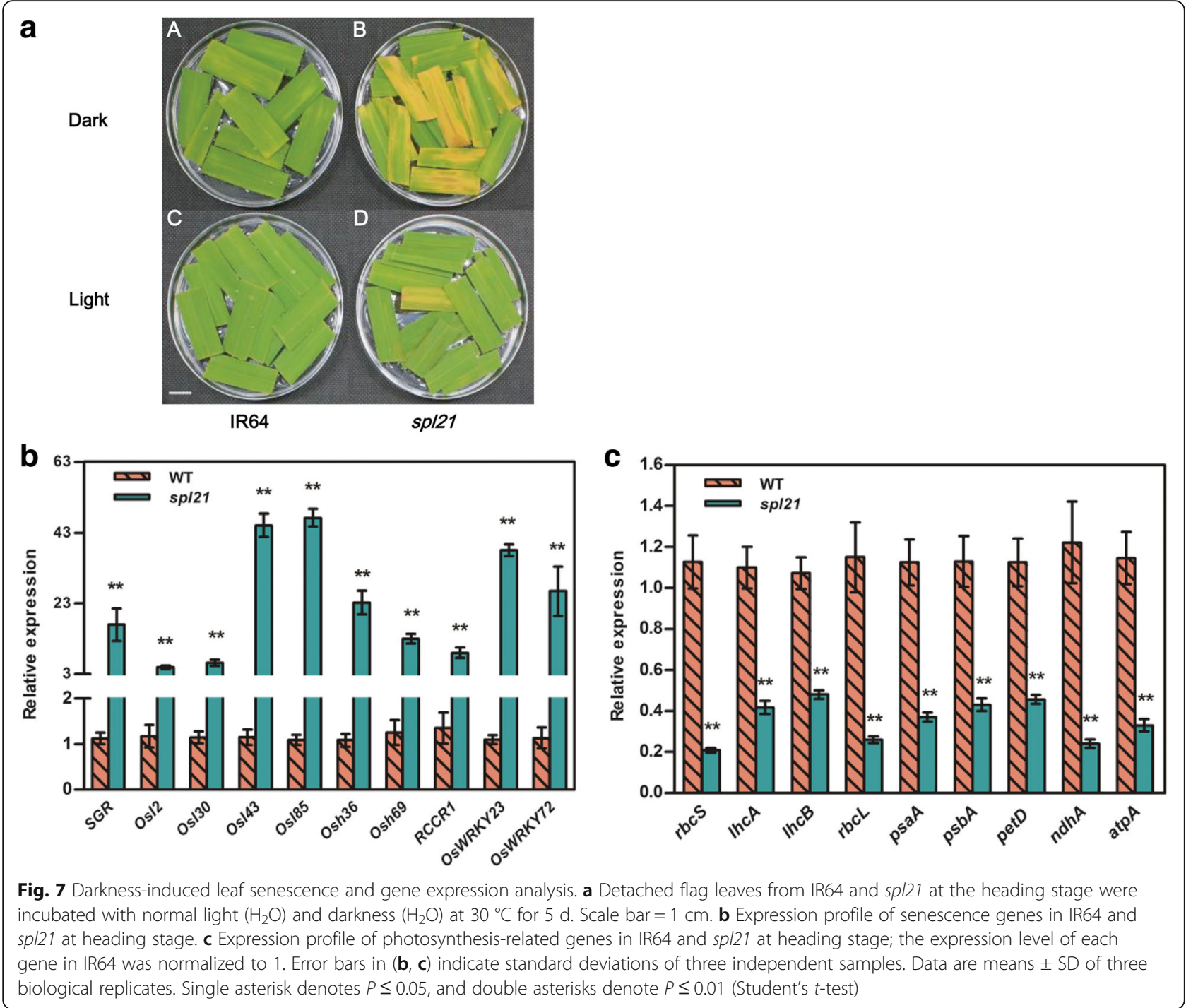

of secondary metabolites, and regulation of defense response.

Among the 4315 DEGs, 28 genes were involved in jasmonate signaling pathway including 18 jasmonate synthesis/degradation-associated genes, 5 WRKY genes, 3 phenylalanine ammonia-lyase (PAL) genes and 2 jasmonate induced-regulated genes (Additional file 3: Table S1). 20 out 28 genes including 10 cytochrome P450-econding genes, 2 WRKY, 3 PAL, OsJAZ9, OsOPR1, OsSL were upregulated by $2.4-50.1$ folds while the other remaining 8 genes were down-regulated by $2-28.1$ folds. To validate, we chose $10 \mathrm{JA}$ signaling pathway-associated genes for qRT-PCR analysis. Our qRT-PCR results showed that the mRNAs levels of OsLOX1, OsJAZ9, OsOPR1, OsSL OsWRKY42, OsWRKY48, OsPAL2, OsPAL5 and OsPAL7 in $s p l 21$ were highly increased by 5.7-, 9.0-, 38.1-, 30.3-, 22.5-, 7.5-, 5.0-, 5.8-fold, respectively, compared to those of WT (Additional file 4: Figure S1). In contrast, the expressions of OsLOX7 and OsWRKY82 were down-regulated by 2.4- and 2.3-fold compared with WT, respectively. These results were consistent with those of transcriptome sequencing results. Thus, we illustrated that the JA-mediated signaling pathway was probably constitutively activated in $s p l 21$.

To investigate whether the gene expression alteration is associated with the content of endogenous plant hormones including MeJA, SA, IAA, GA3 and ABA, we measured the hormone levels of WT and spl21 at the tillering stage. The results showed that the levels of MeJA, IAA, and GA3 in spl21 were 11.5-, 2.34-, 2.25-fold, respectively, compared to the levels of WT, whereas the level of ABA decreased by $34.3 \%$ (Fig. 9). These results suggested that the enhanced disease resistance of spl21 was probably resulted from the activation of the JA-mediated signaling pathway and inactivation of ABA-mediated signaling pathway. 

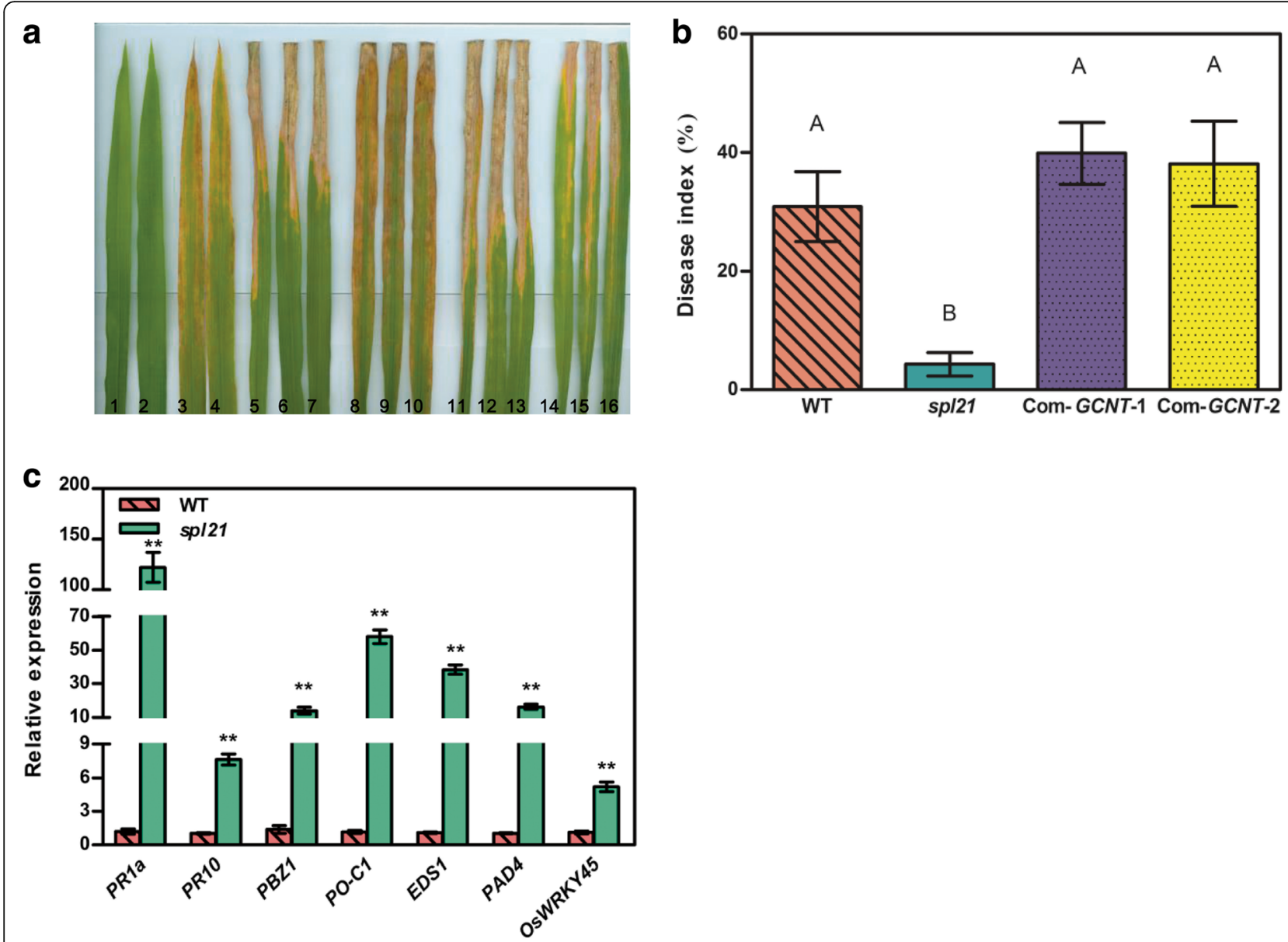

Fig. 8 Evaluation of disease resistance and expression of defense signaling-related genes in sp/21 and WT. a Reactions to XOO race PXO99. 1-2: WT before inoculation; 3-4: sp/21 before inoculation; 5-7: WT after inoculation; 8-10: sp/21 after inoculation; 11-16: complementation lines. b Mean lesion length/leaf length radio after inoculation of plant leaves with PXO99. Data represent the lesion length means \pm SD from 5 independent plants at the tillering stage (Student's $t$-test: ${ }^{*}, P \leq 0.01$ ). c Relative expression of seven defense signaling-related genes in WT and sp/21 at the tillering stages analyzed by qRT-PCR. The expression level of each gene in WT was normalized to 1; data represent the mean \pm SD of three biological replicates (Student's $t$-test: ${ }^{*}, P \leq 0.01$ )

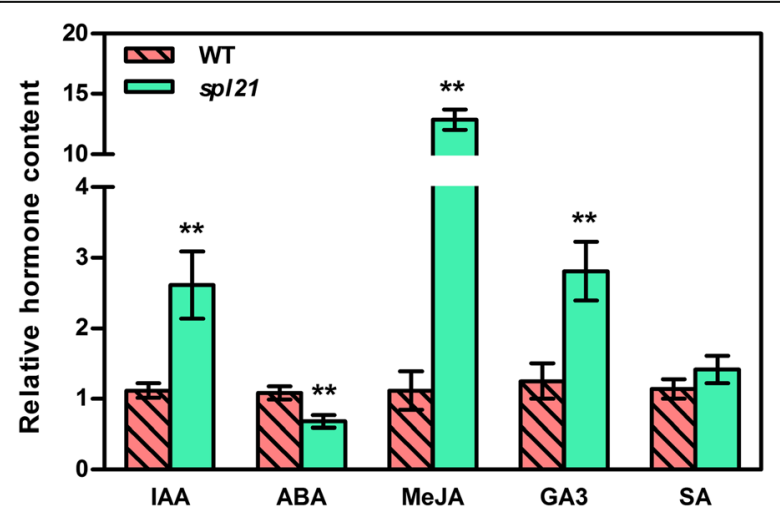

Fig. 9 Hormone levels in leaves of spl21 and WT. IAA, indole acetic acid; ABA, abscisic acid; MeJA, jasmonate; GA3, gibberellin A3; SA, salicylic acid. Data represent means \pm SD of three biological replicates. Single asterisk denotes $P \leq 0.05$, and double asterisks denote $P \leq 0.01$ (Student's t-test)

\section{Discussion}

Functional inactivation of OsGCNT is responsible for the spotted-leaf phenotype

In the present study, we demonstrate that the mutant GCNT allele has a single nucleotide replacement (A836G) leading to the amino acid substitution (Y279C) in the translated protein (Fig. 1). Functional Complementation with the wild type allele could rescue the phenotype in spl21 (Fig. 2). The amino acid sequence alignment indicates that GCNT proteins contain a Branch domain conserved in a wide range of organisms (Fig. 3). There are two types of beta-1,6-N-acetylglucosaminyl transferase, I-branching GCNT and core-2 branching GCNT. These GCNTs display different biological functions as the I-branching enzyme could produce the blood group I-antigen while core-2 branching enzyme constitutes the crucial side-chain branches in O-glycans $[39,40]$. RNA-seq analysis of spl21 and WT demonstrated 
that both 'catalytic activity' GO terms in molecular function and 'biosynthesis of secondary metabolites' in KEGG pathways were significantly higher enriched (Additional file 1: Dataset 1 and Additional file 2: Dataset 2). These results indicate that OsGCNT may be involved in catalyzing the modification of biological molecules, the typical role of glycosyltransferase in biosynthetic processes. Therefore, we assume that OsGCNT is likely to fulfill the functions of beta-1,6-N-acetylglucosaminyl transferase. However, further investigation is needed to distinguish which type of beta-1,6-N-acetylglucosaminyl transferase to which OsGCNT belongs.

OsGCNT is constitutively expressed in all tissues and expressed at all developmental stages in the WT plants (Fig. 4). The subcellular location of OsGCNT shows that OsGCNT-GFP mainly localizes to the Golgi apparatus in rice (Fig. 5). In addition, 'vesicle', 'cytoplasmic membrane-bounded vesicle' and 'cytoplasmic vesicle' GO terms in cellular component are highly enriched within the up-regulated genes (Additional file 1: Dataset 1, up-regulated group). It is known that the plant Golgi apparatus consists of individual stacks of membrane bound flattened cisternae surrounded by small vesicles that are dispersed throughout the cytoplasm [41].Thus, our results imply that OsGCNT may involve in transportation of cellular vesicles. It has been shown that N-acetylglucosaminyltransferase I (GCSI) from Arabidopsis localizes to the ER, while $3-1,2$-xylosyltransferase is exclusively targeted to Golgi apparatus [42]. Furthermore, the human GCNT1 and GCNT2 both locate to the Golgi apparatus [43]. These relevant evidences and subcellular location of the fusion protein OsGCNT-GFP in the present study support that OsGCNT localizes to the Golgi apparatus. However, we have not yet tested whether OsGCNT-GFP is a functional version that can complement the spl21 phenotype. Therefore, the actual intracellular location of OsGCNT till now is not certain and needs to be elucidated in the future.

The single nucleotide replacement (A836G) causes the amino acid substitution (Y279C) in the OsGCNT protein sequence and is responsible for the defective phenotype in $s p l 21$. To the best of our knowledge, this is the first report of a rice beta-1,6-N-acetylglucosaminyl transferase mutant which displays a typical spotted-leaf phenotype.

\section{Loss-of-function of OsGCNT induces innate immunity and immunity-associated premature leaf senescence}

The spl21 senescence symptoms appear at the four-leaf stage seedlings based on our previous study [33]. In recent years, several studies have shown that the premature leaf senescence is accompanied by the spotted-leaf phenotype although the mechanisms underlying premature leaf senescence has not been fully clarified in these mutants $[3,21,24]$. Consequently, it is important to confirm that the premature leaf senescence does really occur in spl21 using senescence indicators including the decrease of chlorophyll content [15], chloroplast breakdown [24], dark-induced senescence [35], up-regulation of senescence-associated genes [3, 38, 44, 45], and downregulation of photosynthesis-related genes [21]. We found that chloroplast degradation in spl21 (Fig. 6) was coincident with the premature leaf senescence process similar to rice spl128 [24]. Senescence-associated genes such as chlorophyll degradation regulated gene (SGR) [38], breakdown of chlorophyll metabolism-related gene (RCCR1) [44], senescence-associated transcription factors (OsWRKY23 and OsWRKY72) [45], and senescence associated genes Osl2, Osl30, Osl43, Osl85, Osh36, Osh69 [3], were significantly up-regulated in spl21 (Fig. 7b). Furthermore, a set of photosynthesis-related genes were prominently down-regulated in spl21 (Fig. 7c). All these evidences support that premature leaf senescence occurs in spl21. We therefore conclude that OsGCNT participates indirectly in the regulation of leaf senescence.

Many spl mutants exhibit the upregulated expression of defense response genes and spontaneous appearance of HR-like lesions, both of which may contribute to enhanced resistance to pathogens [5]. In our present study, we demonstrate that the spl21 mutant acquired systemic resistance to compatible strains of rice bacterial leaf blight pathogen compared to both WT and complementary plants (Fig. 8a, b), suggesting that OsGCNT serves as a negative regulator of defense response in rice. Enhanced defense response can also be reflected by the up-regulation of defense response-associated genes such as PR1a, PR10, PBZ1, PO-C1, EDS1, PAD4 and OsWRKY45 which have commonly been used as molecular markers for rice defense response [14, 19]. As expected, the expression level of defense response-associated genes (PR1a, PR10, PBZ1, PO-C1, EDS1, PAD4 and OsWRKY45) were all increased remarkably in $s p l 21$ after the initiation of leaf lesions (Fig. 8c), suggesting that OsGCNT is involved in enhancing defense response. Whether defense response occurs before the initiation of lesions remains to be investigated.

\section{JA may play an important role in innate immunity and immunity-associated senescence in sp/21}

Plant small-molecule hormones such as SA, JA, and ABA play important regulatory roles in most biological processes of plants, including promote or delay of the leaf senescence and up-, down-regulate of defense response genes [7]. MeJA acts as dominating cellular regulator modulating leaf senescence in JA signaling pathways [46]. In the present study, endogenous MeJA levels were significantly elevated in spl21 (Fig. 9). It has been shown that MeJA could cause rapid chlorophyll loss and induce the expression of several key enzymes involved in chlorophyll 
breakdown [47], and furthermore, exogenous application of MeJA induces leaf senescence and increases the accumulation of secondary metabolites in various plant species $[48,49]$. Furthermore, MeJA-induced senescence is not associated with the level of endogenous ABA in detached rice leaves [50]. These results suggest that the premature leaf senescence in spl21 is mainly modulated by the increased level of MeJA while it is still essential to further investigate the molecular mechanism underlying leaf senescence mediated by endogenous MeJA level.

Furthermore, consistent with the higher endogenous MeJA content (Fig. 9), multiple genes involved in response to JA were activated in spl21 (Additional file 3: Table S1, Additional file 4: Figure S1), supporting the notion that resistance to Xoo was enhanced via the JA-mediated pathway. It has been identified that the 12-oxo-phytodienoic acid reductase gene OsOPR1 encoded the last committed enzymatic step on the octadecanoid pathway leading to jasmonic acid (JA) biosynthesis [51]. Transcription of the OsOPR1 is shown to be JA-inducible and the increase of OsOPR1 mRNA levels by JA does not appear to require de novo synthesis of proteins [51]. Increased expressions of pea $L O X s$ have been identified along with the release of signal molecules like MeJA [52]. In rice, CYP450 enzyme is proved to be involved in JA signaling pathway [53]. OsJAZ9 has been proved to be involved in JA signaling pathway acting as a transcriptional regulator modulating salt stress tolerance in rice [54]. Considering the key role of JA in plant disease resistance, we therefore reason that the highly accumulated MeJA in spl21 is probably involved in OsGCNT-mediated defense response although the molecular mechanism underlying the resistance to Xoo remains elusive.

\section{Conclusions}

In the present study, we reported the map-based cloning of a novel gene Oryza sativa beta-1,6-N-acetylglucosaminyl transferase (OsGCNT) responsible for the spotted-leaf phenotype of spl21. The loss of function of OsGCNT induced enhanced disease resistance to Xoo in spl21. The novel OsGCNT, acting as a negative regulator, modulated rice innate immunity and immunity-associated leaf senescence probably by activating the jasmonate signaling pathway.

\section{Methods}

\section{Plant materials}

The spotted-leaf mutant spl21 was isolated from an ethane methyl sulfonate (EMS) mutagenesis of indica rice cultivar IR64 [5]. The mutant phenotype, spotted leaf and leaf senescence, has been stably inherited over multiple generations. The rice spl21 shows an impaired growth and spotted-leaf lesions from the four-leaf stage to the ripening stage. Furthermore, agronomic traits, such as plant height, number of tillers/plant, seed-setting rate, and 1000-grain weight, were significantly decreased in the spl21 mutant in contrast to the wild-type (WT) IR64 [33]. spl21 and WT were planted both in the greenhouse and the paddy field under normal water and fertilizer management at the China National Rice Research Institute (CNRRI) in 2017.

\section{Complementation test}

To construct a vector for functional complementation, an 5557 bp DNA genomic fragment from WT containing 1619 bp upstream of the OsGCNT transcription start site, the full-length OsGCNT genomic DNA, and $1473 \mathrm{bp}$ downstream of the OsGCNT termination site was amplified by LA taq polymerase (Takara Inc.) using the primer set 28com (Additional file 5: Table S2). The $5557 \mathrm{bp}$ fragment was then cloned into the binary vector pCAMBIA1300 to generate a new construct pC1300-C. The construct was used to transform embryogenic calli induced from spl21 seeds using the Agrobacterium tumefaciens-mediated method [55]. Positive transgenic plants were confirmed using Bar178 primers (Additional file 5: Table S2) specific for the amplification of the phosphinothricin screening gene.

\section{Multiple sequence alignment}

The Rice Genome Annotation Project (http://rice.plantbiology.msu.edu/) and the Simple Modular Architecture Research Tools program (http://smart.embl-heidelberg.de/ ) were respectively used to predicted gene and the major functional domains of OsGCNT. The NCBI Blastp search program (http://www.ncbi.nlm.nih.gov/) was used to search protein homologous sequences to OsGCNT. The sequences of GCNT were aligned using DNAMAN v6.0 (http://www.lynnon.com/) and the neighbor-joining tree was conducted using the software MEGA v7.1 (http:// www.megasoftware.net/).

\section{RNA extraction and quantitative real-time PCR analysis} Total RNA was extracted from various plant tissues using NucleoZOL Reagent Kit according to the manufacturer's protocol (MACHEREY-NAGEL GmbH \& Co. KG). The genomic DNA removal and the first stand cDNA synthesis were carried out using the ReverTra Ace qPCR RT Master Mix Kit (Toyobo, Japan). Fast Star Essential DNA Green Master Kit (Roche, Switzerland) was chosen for qRT-PCR analysis and performed on a Thermal Cycle Dice ${ }^{\oplus}$ Real Time System (TaKaRa, Japan). An ubiquitin gene (LOC_OsO3g13170) was used as an internal control. Primers used for qRT-PCR are listed in Additional file 5: Table S2. Three replicates were used for each biological sample and the means were used for analysis. 


\section{Subcellular localization of OsGCNT protein}

The full-length coding sequence (no stop codon) of OsGCNT was amplified using the primers SPL21-GFP F/R (Additional file 5: Table S2). The PCR product of OsGCNT was fused to the GFP N-terminus and driven by the CaMV $35 \mathrm{~S}$ promoter in the transient expression vector PAN580 to generate a new construct designated as pOsGCNT-GFP. The construct was co-transformed in rice protoplasts with the marker plasmid ST-RFP [56], and transfected protoplasts were incubated as described previously [57]. The GFP fluorescence was observed $48 \mathrm{~h}$ after transformation by a Zeiss $1 s m 710$ confocal laser scanning microscope (Carl Zeiss, Inc., Jena, Germany).

\section{Analysis of pigment and transmission electron microscopy} Leaf samples from spl21, WT and complemented plants were used to determine contents of $\mathrm{Chl} \mathrm{a}, \mathrm{Chl} \mathrm{b}, \mathrm{Chl} \mathrm{T}$ and $\mathrm{Car}$ at the tillering stage following the method of Wellburn [58]. Leaves of the control plants at the same stage were used for comparison analysis. Transverse sections of leaves from WT and spl21 leaves with lesions were used for transmission electron microscopy observation according to the method described previously [59].

\section{Dark-induced senescence}

At the heading stage, the flag leaves were cut into $\sim 3 \mathrm{~cm}$ pieces and floated on $20 \mathrm{~mL}$ of distilled water in Petri dishes. The leaf samples were incubated at $30{ }^{\circ} \mathrm{C}$ in darkness and normal light for 5 days in a growth chamber with daily cycles of $10 \mathrm{~h}$ of light and $14 \mathrm{~h}$ of darkness.

\section{Disease resistance evaluation}

The virulent Xanthomonas oryzae pv. oryzae strain PXO99 (Philippine race 6) was routinely cultured in a peptone sucrose agar medium. A total of 6-8 leaf blades including the upper-most fully expanded leaves from both the main and lateral tillers of WT, spl21 and 2 complemented plants were inoculated with a bacterial suspension $\left(\mathrm{OD}_{600}=1.0\right)$ using the leaf clipping method [60]. Lesion length was measured 12 days after inoculation. The lesion length means of 5 leaf blades were used for analysis.

\section{Hormone level determination}

The levels of indole-3-acetic acid (IAA), methyl jasmonate (MeJA), gibberellin 3 (GA3), salicylic acid (SA) and abscisic acid $(\mathrm{ABA})$ at the tillering stage were determined by Zoonbio Biotechnology Co., Ltd., following the methods described previously by Zhang et al. [27]. The means of three replicates were used for analysis.

\section{Transcriptome sequencing and data analysis}

To eliminate other possible mutations, the $\mathrm{BC}_{2} \mathrm{~F}_{3}$ population was derived from the cross between spl21 mutant and WT IR64. Top-second leaves from 3 individual $\mathrm{BC}_{2} \mathrm{~F}_{3}$ mutant plants and 3 individual WT plants at heading stage were used for RNA isolation after grinding in liquid nitrogen. A total of 6 RNA samples were used for RNA-seq analysis and Q-RT-PCR conformation. The RNA samples were quantified using an Agilent 2100 Bioanalyzer system (Agilent Technologies, Waldbronn, Germany) before sequencing analysis. High-throughput sequencing was performed on an Illumina HiSeq 3000 platform (Illumina, San Diego, CA, USA) following the manufacturer's recommendations. The aligned read files were processed by Cufflinks [61]. The unit of measurement is Fragment Per Kilobase of exon per Million fragments mapped (FPKM). Differentially expressed genes (DEGs) and transcript expression analysis between three biological replicates of either spl21 and IR64 were performed using the Empirical Analysis of Digital Gene Expression data package in Cuffdiff (ver.2.1.1). An absolute fold change of $>2$ and a False Discovery Rate (FDR) significance score of $\leq 0.05$ were used as thresholds to identify significant differences in gene expression. Gene Ontology (GO) annotations of DEGs were obtained from the Rice Genome Annotation Project. GO functional enrichment and Kyoto Encyclopedia of Genes and Genomes (KEGG) analysis were performed as described previously [62].

\section{Additional files}

Additional file 1: Dataset 1. GO enrichment analysis of DEGs. (XLS 69 kb) Additional file 2: Dataset 2. Functional enrichment analysis of DEGs based on KEGG metabolic pathways. (XLS $52 \mathrm{~kb}$ )

Additional file 3: Table S1. JA biosynthesis-associated genes between the IR64 and spl21 plants in DEGs. (DOCX 23 kb)

Additional file 4: Figure S1. qRT-PCR validation of 10 genes expressed in IR64 and spl21. (DOCX $340 \mathrm{~kb}$ )

Additional file 5: Table S2. Primers used in this study. (DOCX 24 kb)

\section{Abbreviations}

ABA: Abscisic acid; Car: Carotenoid; CAZy: Carbohydrate Active Enzyme; CDS: Coding sequence; Chl a: Chlorophyll a; Chl b: Chlorophyll b; DEG: Differentially expressed gene; EMS: Ethane methyl sulfonate; FDR: False discovery rate; GA3: Gibberellin 3; GCNT: Beta-1,6-N-acetylglucosaminyl transferase; GO: Gene Ontology; GT: Glycosyltransferase; HR: Hypersensitive response; IAA: Indole-3-acetic acid; JA: Jasmonic acid; KEGG: Kyoto Encyclopedia of Genes and Genomes; LMM: Lesion mimic mutant; MDA: Malonaldehyde; MeJA: Methyl jasmonate; PCD: Programmed cell death; qRT-PCR: Quantitative real-time reverse transcription-PCR; RNAseq: High-throughput mRNA sequencing; SA: Salicylic acid; SAG: Senescenceassociated gene; spl: spotted-leaf; TEM: Transmission electron microscopy; TF: Transcription factor; WT: Wild type; Xoo: Xanthomonas oryzae pv. oryzae

\section{Acknowledgements}

We would like to thank the reviewers and editors for the suggestions and comments, and Dr. Lei Wang for language editing.

Funding

Funding for this project was provided by the National Natural Science Foundation of China (No. 31471572) and the Ministry of Science and Technology of China (2016YFD0101104). The funding agent only provided 
the financial support and did not involve in the design of the experiment, collection, interpretation and analysis of data and in the drafting of the manuscript.

\section{Availability of data and materials}

The datasets used and/or analyzed during the current study are available from the corresponding author on reasonable request.

\section{Authors' contributions}

$X X, X Z$ and JW conceived and designed the research, XX, XZ, HW, and YS performed the experiments, YH, ZC, TC, and LS carried out the data analysis, XX, XZ and JW wrote and revised the manuscript. All authors read and approved the final manuscript.

\section{Ethics approval and consent to participate}

Not applicable.

\section{Consent for publication}

Not applicable.

\section{Competing interests}

The authors declare that they have no competing interests.

\section{Publisher's Note}

Springer Nature remains neutral with regard to jurisdictional claims in published maps and institutional affiliations.

\section{Received: 24 May 2018 Accepted: 17 October 2018}

\section{Published online: 01 November 2018}

\section{References}

1. Wertman J, Lord CE, Dauphinee AN, Gunawardena AH. The pathway of cell dismantling during programmed cell death in lace plant (Aponogeton madagascariensis) leaves. BMC Plant Biol. 2012;12:115.

2. Fekih R, Tamiru M, Kanzaki H, Abe A, Yoshida K, Kanzaki E, Saitoh H, Takagi H, Natsume S, Undan JR, Undan J, Terauchi R. The rice (Oryza sativa L.) LESION MIMIC RESEMBLING, which encodes an AAA-type ATPase, is implicated in defense response. Mol Gen Genomics. 2015;290(2):611-22.

3. Wang $S A$, Lei $C L$, Wang JL, Ma J, Tang S, Wang CL, Zhao KJ, Tian P, Zhang H, Qi CY, Cheng ZJ, Zhang X, Guo XP, Liu LL, Wu CY, Wan JM. SPL33, encoding an eEF1A-like protein, negatively regulates cell death and defense responses in rice. J Exp Bot. 2017;68(5):899-913.

4. Xu X, Zhang L, Liu B, Ye Y, Wu Y. Characterization and mapping of a spotted leaf mutant in rice (Oryza sativa). Genet Mol Biol. 2014;37(2):406-13.

5. Wu CJ, Bordeos A, Madamba MRS, Baraoidan M, Ramos M, Wang GL, Leach JE, Leung $\mathrm{H}$. Rice lesion mimic mutants with enhanced resistance to diseases. Mol Gen Genomics. 2008:279(6):605-19.

6. Feng BH, Yang $Y$, Shi YF, Shen HC, Wang HM, Huang QN, Xu X, Lv XG, Wu $J$. Characterization and genetic analysis of a novel rice spotted-leaf mutant HM47 with broad-spectrum resistance to Xanthomonas oryzae pv. Oryzae. J Integr Plant Biol. 2013;55(5):473-83.

7. Thakur N, Sharma V, Kishore K. Leaf senescence: an overview. Ind J Plant Physiol. 2016;21(3):225-38.

8. Gregersen PL, Culetic A, Boschian L, Krupinska K. Plant senescence and crop productivity. Plant Mol Biol. 2013;82(6):603-22.

9. Wang $L$, Pei ZY, Tian YC, He CZ. OsLSD1, a rice zinc finger protein, regulates programmed cell death and callus differentiation. Mol Plant Microbe In. 2005;18(5):375-84

10. Zhou LA, Cheung MY, Zhang Q, Lei CL, Zhang SH, Sun SSM, Lam HM. A novel simple extracellular leucine-rich repeat (eLRR) domain protein from rice (OsLRR1) enters the endosomal pathway and interacts with the hypersensitive-induced reaction protein 1 (OsHIR1). Plant Cell Environ. 2009; 32(12):1804-20.

11. Zhou LA, Cheung MY, Li MW, Fu YP, Sun ZX, Sun SM, Lam HM. Rice hypersensitive induced reaction protein 1 (OsHIR1) associates with plasma membrane and triggers hypersensitive cell death. BMC Plant Biol. 2010; 10(1):1-10.

12. Qiao YL, Jiang WZ, Lee JH, Park BS, Choi MS, Piao RH, Woo MO, Roh JH, Han LZ, Paek NC, Seo HS, Koh HJ. SPL28 encodes a clathrin-associated adaptor protein complex 1, medium subunit $\mu 1$ (AP1M1) and is responsible for spotted leaf and early senescence in rice (Oryza sativa). New Phytol. 2010; 185(1):258-74

13. Sun CH, Liu LC, Tang JY, Lin AH, Zhang FT, Fang J, Zhang GF, Chu CC. RLIN1, encoding a putative coproporphyrinogen III oxidase, is involved in lesion initiation in rice. J Genet Genomics. 2011;38(1):29-37.

14. Tang JY, Zhu XD, Wang YQ, Liu LC, Xu B, Li F, Fang J, Chu CC. Semi-dominant mutations in the CC-NB-LRR-type R gene, NLS1, lead to constitutive activation of defense responses in rice. Plant J. 2011;66(6):996-1007.

15. Jiao BB, Wang JJ, Zhu XD, Zeng LJ, Li Q, He ZH. A novel protein RLS1 with NB-ARM domains is involved in chloroplast degradation during leaf senescence in rice. Mol Plant. 2012;5(1):205-17.

16. Chen X, Hao L, Pan J, Zheng X, Jiang G, Jin Y, Gu Z, Qian Q, Zhai W, Ma B. SPL5, a cell death and defense-related gene, encodes a putative splicing factor 3b subunit3 (SF3b3) in rice. Mol Breeding. 2012;30(2):939-49.

17. Jin B, Zhou XR, Jiang BL, Gu ZM, Zhang PH, Oian Q, Chen XF, Ma BJ. Transcriptome profiling of the spl5 mutant reveals that SPL5 has a negative role in the biosynthesis of serotonin for rice disease resistance. Rice. 2015; $8(1): 18-28$.

18. Kim JA, Cho K, Singh R, Jung YH, Jeong SH, Kim SH, Lee JE, Cho YS, Agrawal GK, Rakwal R, Tamogami S, Kersten B, Jeon JS, An GH, Jwa NS. Rice OSACDR1 (Oryza sativa cccelerated cell death and resistance 1) is a potential positive regulator of fungal disease resistance. Mol Cells. 2009;28(5):431-9.

19. Wang SH, Lim JH, Kim SS, Cho SH, Yoo SC, Koh HJ, Sakuraba Y, Paek NC. Mutation of SPOTTED LEAF3 (SPL3) impairs abscisic acidresponsive signalling and delays LEAF senescence in rice. J Exp Bot. 2015;66(22):7045-59.

20. Zeng LR, Qu SH, Bordeos A, Yang CW, Baraoidan M, Yan HY, Xie Q, Nahm $B H$, Leung $H$, Wang GL. Spotted leaf11, a negative regulator of plant cell death and defense, encodes a U-box/armadillo repeat protein endowed with E3 ubiquitin ligase activity. Plant Cell. 2004;16(10):2795-808.

21. Wang J, Qu BY, Dou SJ, Li LY, Yin DD, Pang ZQ, Zhou ZZ, Tian MM, Liu GZ, Xie Q, Tang DZ, Chen XW, Zhu LH. The E3 ligase OsPUB15 interacts with the receptor-like kinase PID2 and regulates plant cell death and innate immunity. BMC Plant Biol. 2015;15(1):49-64.

22. Liu QE, Ning YS, Zhang YX, Yu N, Zhao CD, Zhan XD, Wu WX, Chen DB, We XJ, Wang GL, Cheng SH, Cao LY. OsCUL3a negatively regulates cell death and immunity by degrading OsNPR1 in rice. Plant Cell. 2017:29(2):345-59.

23. Wang $Z H$, Wang $Y$, Hong $X, H u$ DH, Liu CX, Yang J, Li Y, Huang YQ, Feng YQ, Gong HY, Li YY, Fang G, Tang HR, Li YS. Functional inactivation of UDP$\mathrm{N}$-acetylglucosamine pyrophosphorylase 1(UAP1) induces early leaf senescence and defence responses in rice. J Exp Bot. 2015:66(3):973-87.

24. Huang QN, Shi YF, Zhang XB, Song LX, Feng BH, Wang HM, Xu X, Li XH, Guo D, Wu JL. Single base substitution in OsCDC48 is responsible for premature senescence and death phenotype in rice. J Integr Plant Biol. 2016;58(1):12-28.

25. Zhao JY, Liu PC, Li CR, Wang YY, Guo LQ, Jiang GH, Zhai WX. LMM5.1 and LMM5.4, two eukaryotic translation elongation factor 1A-like gene family members, negatively affect cell death and disease resistance in rice. J Genet Genomics. 2016;44(2):107-18

26. Yamatani $H$, Kohzuma $K$, Nakano M, Takami $T$, Kato $Y$, Hayashi $Y$, Monden $Y$, Okumoto Y, Abe T, Kumamaru T, Tanaka A, Sakamoto W, Kusaba M. Impairment of $\mathrm{Lhca} 4$, a subunit of $\mathrm{LHCl}$, causes high accumulation of chlorophyll and the stay-green phenotype in rice. J Exp Bot. 2018;69(5). https://doi.org/10.1093/jxb/erx468.

27. Zhang XB, Feng BH, Wang HM, Xu X, Shi YF, He Y, Chen Z, Sathe AP, Shi L, Wu JL. A substitution mutation in OsPELOTA confers bacterial blight resistance by activating the salicylic acid pathway. J Integr Plant Biol. 2018; 60(2):160-72.

28. Lu YC, Yang SN, Zhang JJ, Zhang JJ, Tan LR, Yang H. A collection of glycosyltransferases from rice (Oryza sativa) exposed to atrazine. Gene. 2013; 531(2):243-52.

29. Cao PJ, Bartleya LE, Junga $K H$, Ronalda PC. Construction of a rice glycosyltransferase phylogenomic database and identification of ricediverged glycosyltransferases. Mol Plant. 2008;1(5):858-77.

30. Gu JG, Nishikawa A, Fujiij S, Gasan S, Taniquchi N. Biosynthesis of blood group I and $\mathrm{i}$ antigens in rat tissues identification of a novel beta-1-6-Nacetylglucosaminyltransferase. J Biol Chem. 1992;267(5):2994-9.

31. Sato $T$, Yoneyama $T$, Tobisawa $Y$, Hatakeyama $S$, Yamamoto $H$, Kojima $Y$, Mikami J, Mori K, Hashimoto Y, Koie T, Ohyama C. Core 2 ß-1,6-Nacetylglucosaminyltransferase-1 expression in prostate biopsy specimen is an indicator of prostate cancer aggressiveness. Biochem Biophys Res Commun. 2016;470(1):150-6. 
32. Zhang H, Meng F, Wu S, Kreike B, Sethi S, Chen W, Miller FR, Wu G. Engagement of I-branching $\beta$-1, 6-N-acetylglucosaminyltransferase 2 in breast cancer metastasis and TGF- $\beta$ signaling. Cancer Res. 2011;71(14):4846-56.

33. Song LX, Huang QN, Feng BH, Shi YF, Zhang XB, Xu X, Wang HM, Li XH, Zhao BH, Wu JL. Characterization and gene mapping of a spotted-leaf mutant spl21 in rice (Oryza sativa L.). Acta Agron Sin. 2015:41(10):1519-28.

34. Yin $Y$, Chen $H$, Hahn MG, Mohnen D, Xu Y. Evolution and function of the plant cell wall synthesis-related glycosyltransferase family 8. Plant Physiol. 2010;153(4):1729-46.

35. Liang C, Wang Y, Zhu Y, Tang J, Hu B, Liu L, Ou S, Wu H, Sun X, Chu J. OsNAP connects abscisic acid and leaf senescence by fine-tuning abscisic acid biosynthesis and directly targeting senescence-associated genes in rice. Proc Natl Acad Sci U S A. 2014;111(27):10013-8.

36. Kim HJ, Ryu HJ, Hong SH, Woo HR, Lim PO, Lee IC, Sheen J, Nam HG, Hwang I. Cytokinin-mediated control of leaf longevity by AHK3 through phosphorylation of ARR2 in Arabidopsis. Proc Natl Acad Sci U S A. 2006; 103(3):814-9.

37. Morris KH, Mackerness SA, Page T, John CF, Murphy AM, Carr JP, BuchananWollaston $\mathrm{V}$. Salicylic acid has a role in regulating gene expression during leaf senescence. Plant J. 2000;23(5):677-85.

38. Park SY, Yu JW, Park JS, Li JJ, Yoo SC, Lee NY, Lee SK, Jeong SW, Seo HS, Koh HJ, Jeon JS, Park Yl, Paek NC. The senescence-induced staygreen protein regulates chlorophyll degradation. Plant Cell. 2007;19(5):1649-64.

39. Yeh JC, Ong E, Fukuda M. Molecular cloning and expression of a novel beta-1,6-N-acetylglucosaminyltransferase that forms core 2, core 4, and I branches. J Biol Chem. 1999;274(5):3215-21.

40. Hansen SF, Harholt J, Ai O, Scheller HV. Plant glycosyltransferases beyond CAZy: a perspective on DUF families. Front Plant Sci. 2012;3(2):379-411.

41. Dupree P, Sherrier DJ. The plant Golgi apparatus. Biochim Biophys Acta. 1998;1404(1-2):259-70.

42. Saint-Jore-Dupas C, Nebenführ A, Boulaflous AL, Follet-Gueye ML, Plasson C, Hawes C, Driouich A, Faye L. GomordaVR. Plant N-glycan processing enzymes employ different targeting mechanisms for their spatial arrangement along the secretory pathway. Plant Cell. 2006;18(11):3182-200.

43. Kim S, Miura Y, Etchison JR, Freeze HH. Intact Golgi synthesize complex branched O-linked chains on glycoside primers: evidence for the functional continuity of seven glycosyltransferases and three sugar nucleotide transporters. Glycoconjugate. 2001;18(8):623-33.

44. Pruzinská A, Anders I, Aubry S, Schenk N, Tapernoux-Luthi E, Muller T, Kräutler B, Hörtensteiner S. In vivo participation of red chlorophyll catabolite reductase in chlorophyll breakdown. Plant Cell. 2007;19(1):369-87.

45. Zhou QY, Yu Q, Wang ZQ, Pan YF, Lv WT, Zhu LL, Chen RZ, He GC. Knockdown of GDCH gene reveals reactive oxygen species-induced leaf senescence in rice. Plant Cell Environ. 2013;36(8):1476-89.

46. Seo HS, Song JT, Cheong JJ, Lee YH, Lee YW, Hwang I, Lee JS, Choi YD. Jasmonic acid carboxyl methyltransferase: a key enzyme for jasmonateregulated plant responses. PNAS. 2001:98(8):4788-93.

47. Reinbothe C, Springer A, Samol I, Reinbothe S. Plant oxylipins: role of jasmonic acid during programmed cell death, defence and leaf senescence. FEBS J. 2009;276(17):4666-81.

48. Cheong JJ, Choi YD. Methyl jasmonate as a vital substance in plants. Trends Genet. 2003;19(7):409-13.

49. Zhao J, Davis $L C$, Verpoorte R. Elicitor signal transduction leading to production of plant secondary metabolites. Biotechnol Adv. 2005;23(4):283-333.

50. Wang J, Kao CH. Endogenous abscisic acid levels are not linked to methyl jasmonate-promoted senescence of detached rice leaves. J Plant Growth Regul. 2004;28:17-20.

51. Jang S, Cho K, Shibato J, Han O, Iwahashi H, Tamogami S, Zargar SM, Kubo A, Masuo Y, Agrawal GK, Rakwal R. Rice OsOPRs: transcriptional profiling responses to diverse environmental stimuli and biochemical analysis of OsOPR1. J Plant Biol. 2009;52(3):229-43.

52. Chen Z, Chen X, Yan HW, Li WW, Li Y, Cai RH, Xiang Y. The lipoxygenase gene family in poplar identification, classification, and expression in response to MeJA treatment. PLoS One. 2015;10(4):e0125526.

53. Fujiwara T, Maisonneuve $S$, Isshiki M, Mizutani M, Chen LT, Wong HL, Kawasaki T, Shimamoto K. Sekiguchi lesion gene encodes a cytochrome P450 monooxygenase that catalyzes conversion of tryptamine to serotonin in rice. J Biol Chem. 2010;285(15):11308-13.

54. Wu H, Ye HY, Yao RF, Zhang T, Xiong LZ. OsJAZ9 acts as a transcription regulator in jasmonate signaling and modulates salt stress tolerance in rice. Plant Sci. 2015;232:1-12.
55. Hiei Y, Komari T. Agrobacterium-mediated transformationof rice using immature embryos or calli induced from mature seed. Nat Protoc. 2008;3:824-34

56. Cao H, Guo SY, Xu YY, Jiang K, Jones AM, Chong K. Reduced expression of a gene encoding a Golgi localized monosaccharide transporter (OsGMST1) confers hypersensitivity to salt in rice (Oryza sativa). J Exp Bot. 2011;62(13): 4595-604.

57. Chen S, Tao L, Zeng L, Vega-Sanchez ME, Umemura K, Wang GL. A highly efficient transient protoplast system for analyzing defence gene expression and protein-protein interactions in rice. Mol Plant Pathol. 2010;7(5):417-27.

58. Wellburn A. The spectral determination of chlorophylls $a$ and $b$, as well as total carotenoids, using various solvents with spectrophotometers of different resolution. J Plant Physiol. 1994;144(3):307-13.

59. Sakuraba Y, Han S, Yang H, Piao W, Paek N. Mutation of rice early flowering3.1 (OsELF3.1) delays leaf senescence in rice. Plant Mol Biol. 2016;92(1-2):223-34.

60. Manosalva PM, Bruce M, Leach JE. Rice 14-3-3 protein (GF14e) negatively affects cell death and disease resistance. Plant J. 2011;68(5):777-87.

61. Trapnell C, Roberts A, Goff L, Pertea G, Kim D, Kelley DR, Pimentel H, Salzberg SL, Rinn JL, Pachter L. Differential gene and transcript expression analysis of RNA-seq experiments with TopHat and cufflinks. Nat Protoc. 2014;7(3):562-78.

62. Tang S, Liang H, Yan D, Zhao Y, Han X, Carlson JE, Xia X, Yin W. Populus euphratica: the transcriptomic response to drought stress. Plant Mol Biol. 2013;83(6):539-57.

\section{Ready to submit your research? Choose BMC and benefit from:}

- fast, convenient online submission

- thorough peer review by experienced researchers in your field

- rapid publication on acceptance

- support for research data, including large and complex data types

- gold Open Access which fosters wider collaboration and increased citations

- maximum visibility for your research: over $100 \mathrm{M}$ website views per year

At $\mathrm{BMC}$, research is always in progress.

Learn more biomedcentral.com/submissions 